\title{
Perisynaptic barrier of proteoglycans in the mature brain and spinal cord
}

\author{
Takuro Murakami and Aiji Ohtsuka \\ Department of Human Morphology, Functional Physiology, Biophysiological Science, Okayama University \\ Graduate School of Medicine and Dentistry, Okayama, Japan
}

\begin{abstract}
Summary. Cell bodies and their dendrites of motor neurons, motor-related neurons, and certain other subsets of neurons such as GABAergic interneurons in the mature brain and spinal cord possess intensely negatively charged perineuronal or perisynaptic nets of proteoglycans which are linked to the nerve cell surface glycoproteins. These perineuronal nets of proteoglycans are digested by chondroitinase $\mathrm{ABC}$, hyaluronidase, or collagenase, but not by endo-alpha- $\mathrm{N}$ acetylgalactosaminidase, which is reactive to the nerve cell surface glycoproteins. Aggrecan, versican, neurocan, and brevican are members of a family of chondroitin sulfate proteoglycans that bind to hyaluronan. Neurocan-or brevicandeficient mice showed a regionally heterogeneous composition of proteoglycans in perineuronal nets. Aggrecan glycoforms contribute to the molecular heterogeneity of the perineuronal nets. Proteoglycans such as phosphacan are included in matrix-associated proteoglycans. The extracellular matrix glycoprotein tenascin- $R$ is accumulated in the perineuronal nets. The perineuronal proteoglycans are produced by associated satellite astrocytes just before weaning, while the nerve cell surface glycoproteins are produced by the associated nerve cells at earlier stages after birth. The perineuronal proteoglycans may entrap the tissue fluid and form a perineuronal gel layer which protects the synapses as a "perisynaptic barrier". Degradation of the perineuronal proteoglycans or perisynaptic barrier by treatment with
\end{abstract}

Received April 18, 2003

Address for correspondence: Takuro Murakami, M. D., Ph. D. Professor and Chairman

Department of Human Morphology, Functional Physiology, Biophysiological Science, Okayama University Graduate School of,Medicine and Dentistry, 2-5-1, Shikata-cho, Okayama 700-8558, Japan

Phone: +81-86-235-7088, Fax: +81-86-235-7095

E-mail: em2kai@md.okayama-u.ac.jp chondroitinase $\mathrm{ABC}$ or hyaluronidase reactivates the neuronal plasticity or promotes the functional recovery of a severed nervous system. Another set of perineuronal nets occurs, which are intensely positively charged and contain guanidino compounds. It is considered that these intensely positively charged nets are intermingled with the intensely negatively charged ones of proteoglycans.

\section{Introduction}

Biochemical, histochemical, immunohistochemical and electron microscopic studies of brains and spinal cords in mammals, aves, and other lower vertebrates, including pisces, have shown that certain subsets of neurons possess perineuronal nets of proteoglycans (Bertolotto et al., 1990; Bignami et al., 1992; Atoji and Suzuki, 1992; Margolis and Margolis, 1993; Murakami et al., 1993a, b, c, 1994a, b; Celio and Blümcke, 1994; Ruoslahti, 1996; Brückner et al., 1998; Okamoto et al., 2001; Sayed et al., 2002). The perineuronal nets are mainly composed of chondroitin sulfate proteoglycans that bind to hyaluronic acid (Rauch et al., 1991, 1992; Murakami et al., 1994a, b; Yasuhara et al., 1994; Härtig et al., 1994; Milev, 1998; Fox and Caterson, 2002), and are linked by collagenous ligands to nerve cell surface glycoproteins (Murakami et al., 1999a, b, c). The perineuronal nets of proteoglycans occupy the perisynaptic tissue spaces (Murakami et al., 1994b, 1995b; Takahashi-Iwanaga et al., 1998; Ohtsuka et al., 2000), and protect the synapses as the "perisynaptic barrier" (Murakami et al., 2001b). Degradation of the perineuronal nets or perisynaptic barrier by treatment with chondroitinase $\mathrm{ABC}$ or hyaluronidase reactivates the cortical plasticity or promotes the functional recovery of a severed nervous system (Brückner et al., 1998; Pizzorusso et al., 2002; Fox and Caterson, 2002; Bradbury et al., 2002; Moon et al., 2003), as shall be introduced in this paper. Also included are some findings of brevican-, neurocan- or aggrecan-deficient mice (Murakami et al., 2001a; Matthews et al., 2002), and the 
link proteins (Hirakawa et al., 2000; Bekku et al., 2003) and the intensely positively charged perineuronal nets (Murakami et al., 2001c, d).

\section{Perineuronal nets and proteoglycans}

\section{Histochemical stainings}

The perineuronal proteoglycans were stained with a fine cationic iron colloid at a pH value of 1.0-1.5 (Murakami $e t$ al., 1993a, b, c) (Fig. 1, 2), Fujita's highly concentrated aldehyde fuchsin (Murakami et al., 1994b), Golgi's or Kopsch's silver nitrate (Murakami et al., 1996a, b), Gömöri's ammoniacal silver (Fig. 3) (Murakami et al., 1999b) and Ehrlich's methylene blue (Murakami et al., 1999b). The cationic iron colloid staining of the perineuronal proteoglycans is obliterated by methylation, and not reversed by saponification (Murakami et al., 1994b). The perineuronal proteoglycans were doubly stained with cationic iron colloid and Fujita's aldehyde fuchsin (Murakami et al., 1994b), with cationic iron colloid and Golgi's or Kopsch's silver nitrate (Murakami et al., 1996a, b), with cationic iron colloid and Gömöri's ammoniacal silver (Fig. 4) (Murakami et al., 1999a), and with cationic iron colloid and Ehrlich's methylene blue (Murakami et al., 1999a). Nerve cell surface glycoproteins were labeled by lectin Vicia villosa, Wisteria floribunda or soybean agglutinin (Fig. 5) (Nakagawa, 1986a, b; Kosaka and Heizmann, 1989; Drake et al., 1991; Lüth et al., 1992; Härtig et al., 1992, 1994; Murakami et al., 1994, 1995a). Our double stainings have shown that neurons stained with cationic iron colloid are usually labeled with lectin Vicia villosa, Wisteria floribunda or soybean agglutinin (Fig. 5 Inset, 6, 6 Inset) (Murakami et al., 1995a,b, 1996, 1997). These double stainings have also shown that some cationic iron colloid-stained neurons are not labeled with lectins, and that some lectin-labeled neurons are not stained with cationic iron colloid (Fig. 5 Inset, 6, 6 Inset) (Murakami et al., 1995a, b, 1996, 1997). Similar findings have been obtained in double stainings with methylene blue and lectin Wisteria floribunda agglutinin (Murakami et al., 1999a). These facts may indicate that the perineuronal proteoglycans are independent from the nerve cell surface glycoproteins.

\section{Enzyme digestions}

Cationic iron colloid staining of the perineuronal proteoglycans is not thoroughly erased by sole digestion with chondroitinase $\mathrm{ABC}$; for thorough abolition of this iron colloid staining, supplementary treatments with heparitinase and keratanase are needed before or after the chondroitinase ABC digestion (Murakami et al., 1994b). Cationic iron colloid, aldehyde, and Golgi's silver nitrate stainings of the perineuronal proteoglycans are erased thoroughly by sole digestion with hyaluronidase (Fig. 7A, B) or collagenase (Murakami et al., 1994b; Murakami et al., 1999a, b). Gömöri's ammoniacal silver and Ehrlich's methylene blue stainings are thoroughly erased by sole collagenase digestion (Murakami et al., 1999a, b). Endo-alpha-N-acetylgalactosaminidase thoroughly erases the lectin Vicia villosa, Wisteria floribunda or soybean agglutinin labeling of the nerve cell surface glycoproteins (Murakami et al., 1999b). This enzyme never erases the cationic iron colloid, aldehyde fuchsin, ammoniacal silver or other stainings of the perineuronal proteoglycans (Murakami et al., 1999b). These findings serve to strengthen our view that the perineuronal proteoglycans are independent from the nerve cell surface glycoproteins. Köppe et al. (1997a, b) used chondroitinase $\mathrm{ABC}$, hyaluronidase, trypsin, chymotrypsin, papain, subtilisin and protease for their digestion experiments, and described how the binding of the Wisteria floribun$d a$ agglutinin was abolished in all perineuronal nets after the incubation of sections with chondroitinase ABC. We have confirmed that the binding of the lectin Vicia villosa or soybean agglutinin is also abolished after the chondroitinase $A B C$ incubation. In the lectin labeling of the nerve cell surface glycoproteins, the Wisteria floribunda agglutinin is more effective than the lectin Vicia villosa and soybean agglutinins.

\section{Classical descriptions}

As described above, the perineuronal proteoglycans are doubly reactive to Golgi's or Kopsch's silver nitrate and cationic iron colloid, and also doubly reactive to Ehrlich's methylene blue and cationic iron colloid. Thus, the perineuronal proteoglycans are identical with Golgi's reticular coating (revétement réticulare) (Golgi, 1898; Lipsky, 1989; Murakami et al., 1996a, b) and Cajal's superficial reticulum (red superficial, or reseaux pericellulaires) (Ramón y Cajal, 1897, 1909-1911, 1909 translated by Swanson and Swanson, 1995; Celio et al, 1998; Murakami et al., 1999a).

\section{Distributions}

Our light microscopy of mouse brain and spinal cord sections stained with cationic iron colloid, lectin Vicia villosa agglutinin, or Golgi's silver nitrate has revealed that cell bodies and their dendrites of motor neurons, motor-related 

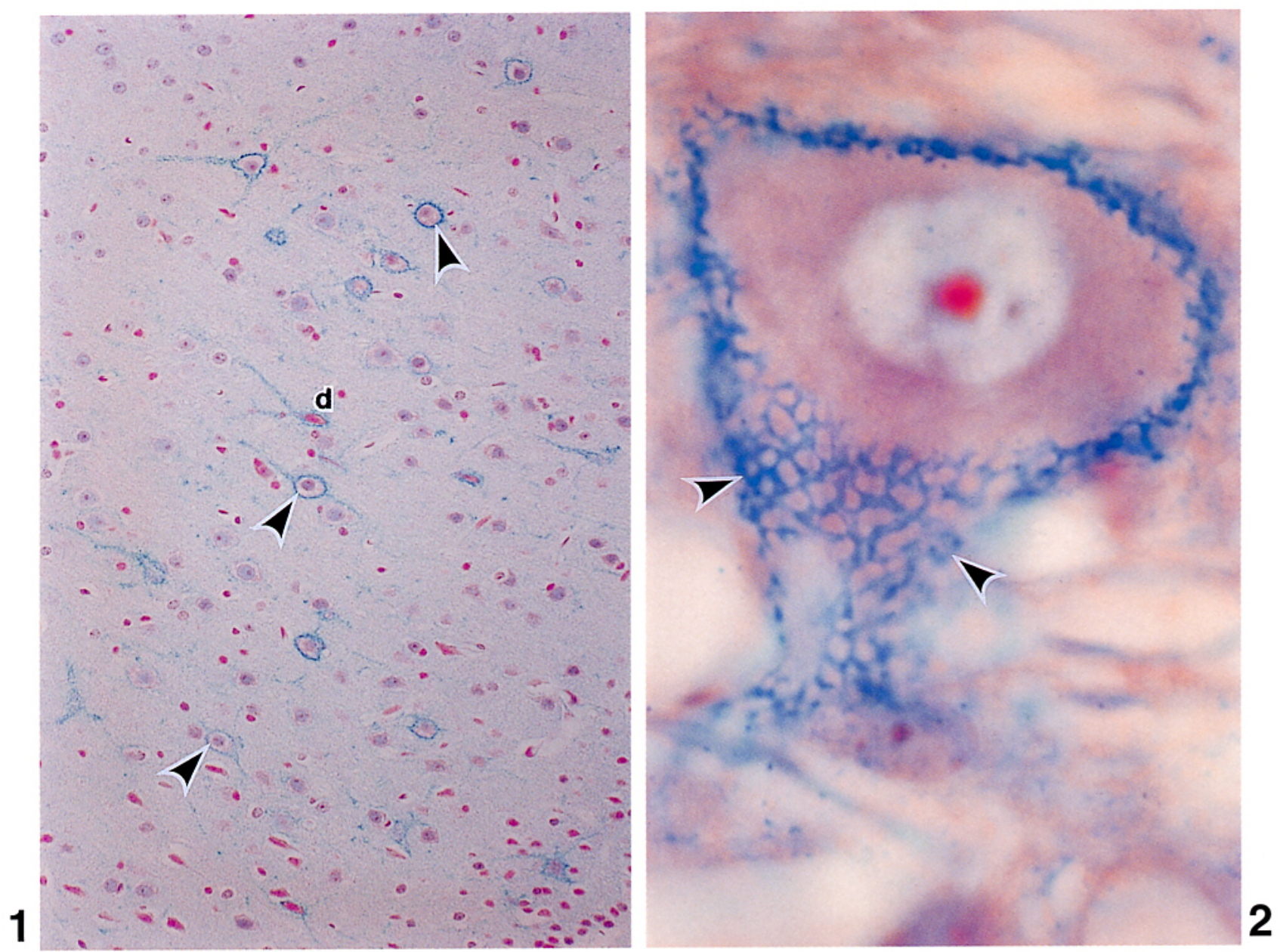

Fig. 1. Survey light micrograph of an adult human brain section traversing the visual cortex (Area 19 of Brodmann), stained with cationic iron colloid $(\mathrm{pH} 1.5)$ and nuclear fast red. Many neurons are covered by an intensely negatively charged perineuronal net of proteoglycans which show an intense Prussian blue reaction (large arrowheads). d: dark neuron. $\times 100$

Fig. 2. Meshworks of an intensely negatively charged perineuronal net of proteoglycans in the human visual cortex, stained with cationic iron colloid and nuclear fast red (large arrowheads) (from Murakami et al., 1994). × 1,500

neurons, some GABAergic interneurons and other neurons such as parvalbumin containing neurons possess the perineuronal nets of proteoglycans or nerve cell surface glycoproteins (Murakami et al., 1996a). In particular, all neurons in the cerebellar nuclei, red nucleus, nucleus of lateral lemniscus, nucleus of the trapezoid body, lateral vestibular nucleus, glomeruli in the granular layer of the corebellar cortex, and anterior horn of the spinal cord possess the perineuronal nets of proteoglycans reactive with cationic iron colloid as well as the nerve cell surface glycoproteins labeled with lectin Vicia villosa. Similar findings have been reported in the rat and human brains by Seeger et al. (1994) and Yasuhara et al. (1994). Seeger et al. (1994) studied the rat brain by colloidal iron hydroxide and lectin cytochemistry. Yasuhara et al. (1994) prepared a monoclonal antibody which specially recognized hyaluronic acid, and used this to stain rat and human brains. Enhanced Prussian blue reaction followed by the Bodian's protein silver impregnation (Hong et al., 2000) makes it obvious that the Purkinje cells in the adult cat cerebellar cortex possess poorly developed or thin perineuronal proteoglycans (Mabuchi et al., 2001), whose occurrences may be omitted by the above experi- 

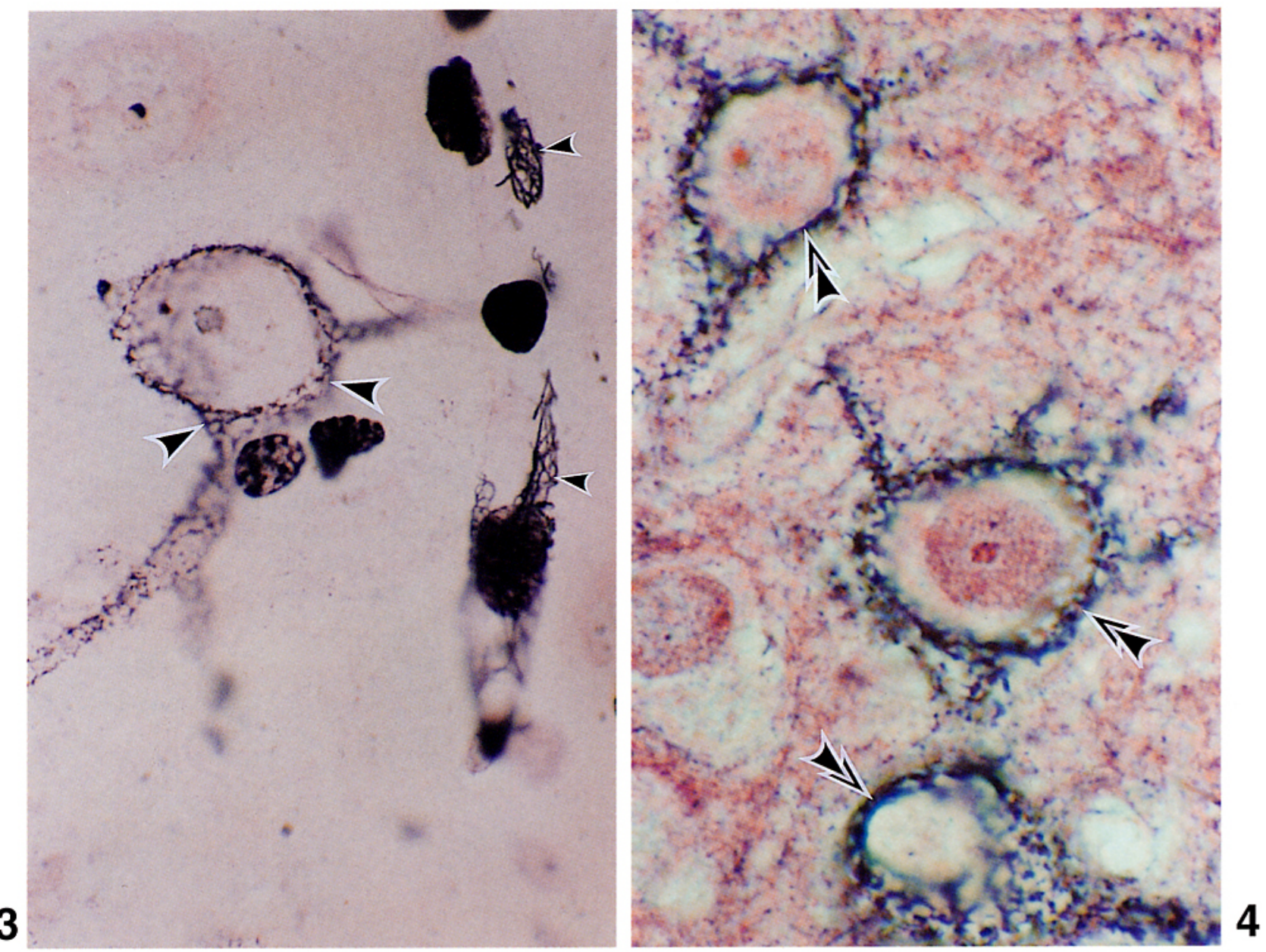

Fig. 3. A section from the retrosplenial cortex of an adult mouse brain, stained with Gömöri's ammoniacal silver (from Murakami et al., 1999a). The perineuronal net stained with ammoniacal silver also shows a meshwork-like structure (large arrowheads). Reticular fibers surrounding the blood capillaries are concomitantly stained with ammoniacal silver (small arrowheads). $\times 1,200$

Fig. 4. Another section from the retrosplenial cortex of an adult mouse brain, successively stained with Gömöri's ammoniacal silver, cationic iron colloid, and nuclear fast red. The perineuronal net is doubly stained with ammoniacal silver and cationic iron colloid (large double arrowheads). $\times 1,300$

ments in the rat and mouse (Seeger et al., 1994; Murakami et al., 1996a).

\section{Development and production}

Our cationic iron colloid and aldehyde fuchsin stainings and lectin (Vicia villosa, Wisteria floribunda, or soybean agglutinin) labelings have indicated that in the mouse brain, the perineuronal proteoglycans are produced by the associ- ated satellite astrocytes 3-4 weeks after birth (immediately before weaning), and the cell surface glycoproteins are produced by the associated nerve cells at earlier stages, or 2-3 weeks after birth (Murakami et al., 1997). In our lectin labelings of newborn mice, this was characterized by the finding that Golgi complexes of the neurons, whose cell surfaces are labeled with lectin Vicia villosa, Wisteria floribunda or soybean agglutinin, are labeled by these lectins (Fig. 8) (Murakami et al., 1997). This confirms that the nerve cell surface glycoproteins are produced by the associ- 

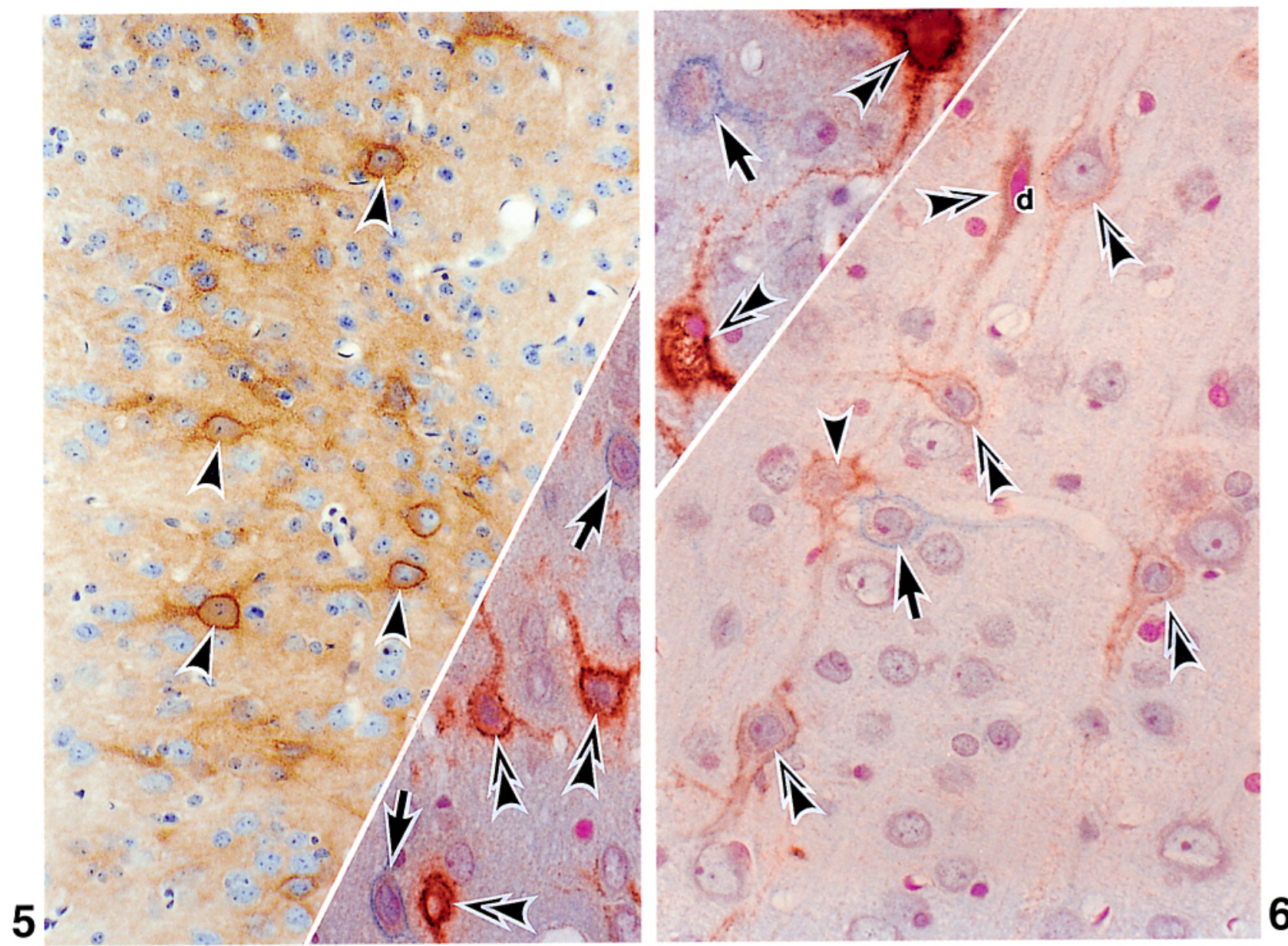

Fig. 5. A section from the human visual cortex treated with lectin soybean agglutinin. Many neurons are labeled by this lectin (large arrowheads). Inset shows a human brain section (visual cortex), stained with lectin Vicia villosa agglutinin (VVA) and cationic iron colloid. Many neurons are doubly stained with lectin VVA and iron colloid (large double arrowheads), and some neurons are solely stained with iron colloid (large arrows). $\times 300$, Inset: $\times 400$

Fig. 6. A section from the human visual cortex treated doubly with lectin soybean agglutinin (SBA) and cationic iron colloid (from Murakami et al., 1995a). The neuron indicated by the large double arrowheads is stained doubly with lectin SBA and cationic iron colloid. The neuron indicated by the large arrowhead is stained solely with lectin SBA. The neuron indicated by the large arrow is stained solely with cationic iron colloid. d: dark neuron. Inset shows a section of human visual cortex, stained with lectin Wisteria floribunda agglutinin (WFA) and cationic iron colloid. Neurons indicated by large double arrowheads are doubly stained with WFA and iron colloid. The neuron indicated by the large arrow is solely stained with iron colloid. $\times 500$, Inset: $\times 500$

ated nerve cells, and gives no evidence supporting the view by Brückner et al. (1993, 1996) and other authors (Blümcke et al., 1955; Derouiche et al., 1996; Köppe et al., 1997a) that the "perineuronal nets" labeled with lectin Vicia villosa, Wisteria floribunda or soybean agglutinin are produced by glial cells (Murakami et al., 1997). Our recent experiments have suggested that some other glial cells such as those containing glial fibrillary acidic protein or those labeled with lectin Solanum tuberosum agglutinin might also participate in the formation of the perineuronal proteoglycans (Fig. 9) (Murakami et al., 2001b; Sayed et al., 2002). 

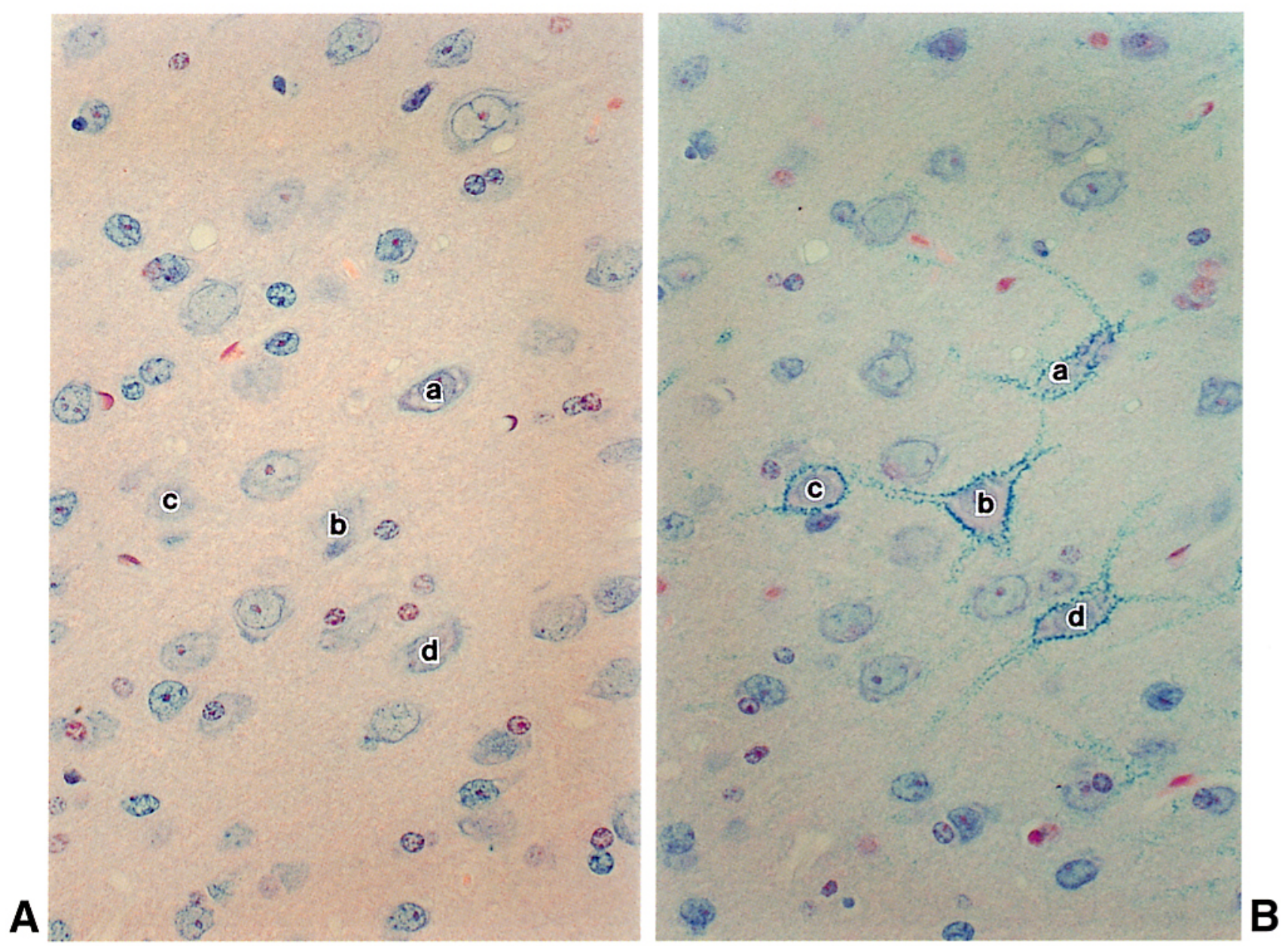

Fig. 7. A: Hippocampal section of an adult mouse, treated with hyaluronidase and stained with cationic iron colloid (from Murakami et al., 1995b). No cell is reactive to the colloid. B: An adjacent control section incubated in a buffer substrate without hyaluronidase and stained with cationic iron colloid. Many cells are reactive to the colloid. The neurons indicated as a-d in A are identical to those in B, respectively (from Murakami et al., 1995b). A and B: $\times 300$

\section{Transmission electron microscopy}

Our transmission electron microscopy of ultrathin sections stained with cationic iron colloid has confirmed that the cationic colloidal iron particles are diffusely and preferentially deposited in the perineuronal or perisynaptic tissue spaces (Fig. 10) (Murakami et al., 1994b, 1995b; Takahashi-Iwanaga et al., 1998; Ohtsuka et al., 2000). This study confirms that the perineuronal proteoglycans occupy the perineuronal or perisynaptic tissue spaces. Transmission electron microscopy of lectin Wisteria floribunda agglutinin-labeled mouse brain sections has shown numerous perisynaptic accumulations of lectin binding sites along the nerve cell body (Brückner et al., 2000).

\section{Neurocan-, brevican-, aggrecan-, or tenascin-R-deficient mice}

The perineuronal proteoglycans are composed of a diverse set of macromolecules (Oohira et al., 2000; Yamaguchi, 2000). Aggrecan, versican, neurocan and brevican are members of a family of chondroitin sulfate proteoglycans that bind to hyaluronan or hyaluronic acid (Milev et al., 1998; Fox and Caterson, 2002). Proteoglycans such as phosphacan are included in matrix-associated proteoglycans (Fox and Caterson, 2002; Winkler et al., 2002). Our studies of neurocan- or brevicandeficient mice (Brakebusch et al., 2002) have shown that in these deficient mice, neither a marked reduction of the cationic iron colloid staining of the perineuronal proteogly- 

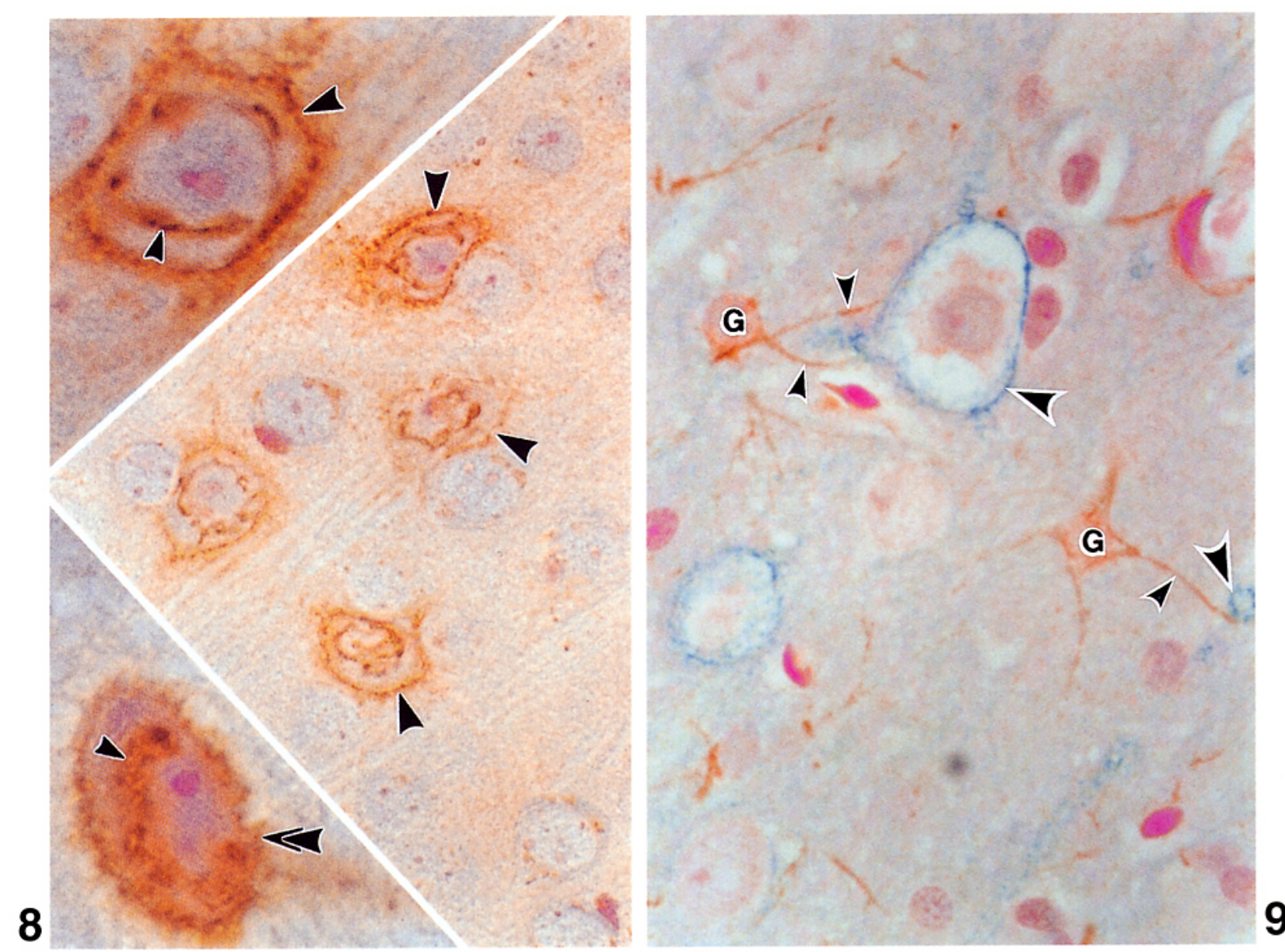

Fig. 8. Retrosplenial section from a newborn mouse 2 weeks after birth, labeled with lectin Vicia villosa agglutinin and counter-stained with nuclear fast red (from Murakami et al., 1997). The cell surface and Golgi complexes of some neurons are intensely labeled with this lectin (large arrowheads). Upper Inset shows a closer view of a light neuron labeled with lectin Vicia villosa agglutinin (large arrowhead). The Golgi complex is intensely labeled with this lectin (small arrowhead), together with the cell surface (large arrowhead). Lower Inset shows a dark neuron (double arrowheads) whose cell surface and Golgi complex (small arrowhead) are labeled with lectin Vicia villosa agglutinin. $\times 700$, Insets: 1,400

Fig. 9. A section of the adult mouse retrosplenial cortex, immunohistochemically stained with an antibody of glial fibrillary acidic protein (GFAP) and then with cationic iron colloid and nuclear fast red (from Murakami et al., 2001b). The GFAP-immunoreactive cells $(\mathrm{G})$ issue some fibers (small arrowheads) which are present in close association to or interlacing with the perineuronal nets of proteoglycans (large arrowheads). $\times 330$

cans nor a marked abolition of the lectin Wisteria floribun$d a$ agglutinin labeling of nerve cell surface glycoproteins was observed in the cerebral cortex (Murakami et al., 2001a) (Fig. 11 upper inset). However, in certain areas such as the cerebellar nuclei, cationic iron colloid staining of the perineuronal nets was markedly abolished in brevicandeficient mice (unpublished data) (Fig. 11). This regional discrepancy may be due to the heterogeneous composition of proteoglycans in perineuronal nets. Some authors have studied aggrecan deficient-mice, and reported that aggrecan glycoforms contribute to the molecular heterogeneity of the perineuronal nets (Matthews et al., 2002). Our enzyme digestion experiments of the human brain indicate that the perineuronal nets additionally contain heparan sulfate and keratan sulfate proteoglycans (Murakami et al., 1994b). The extracellular matrix glycoprotein tenascin-R, colocalizing 


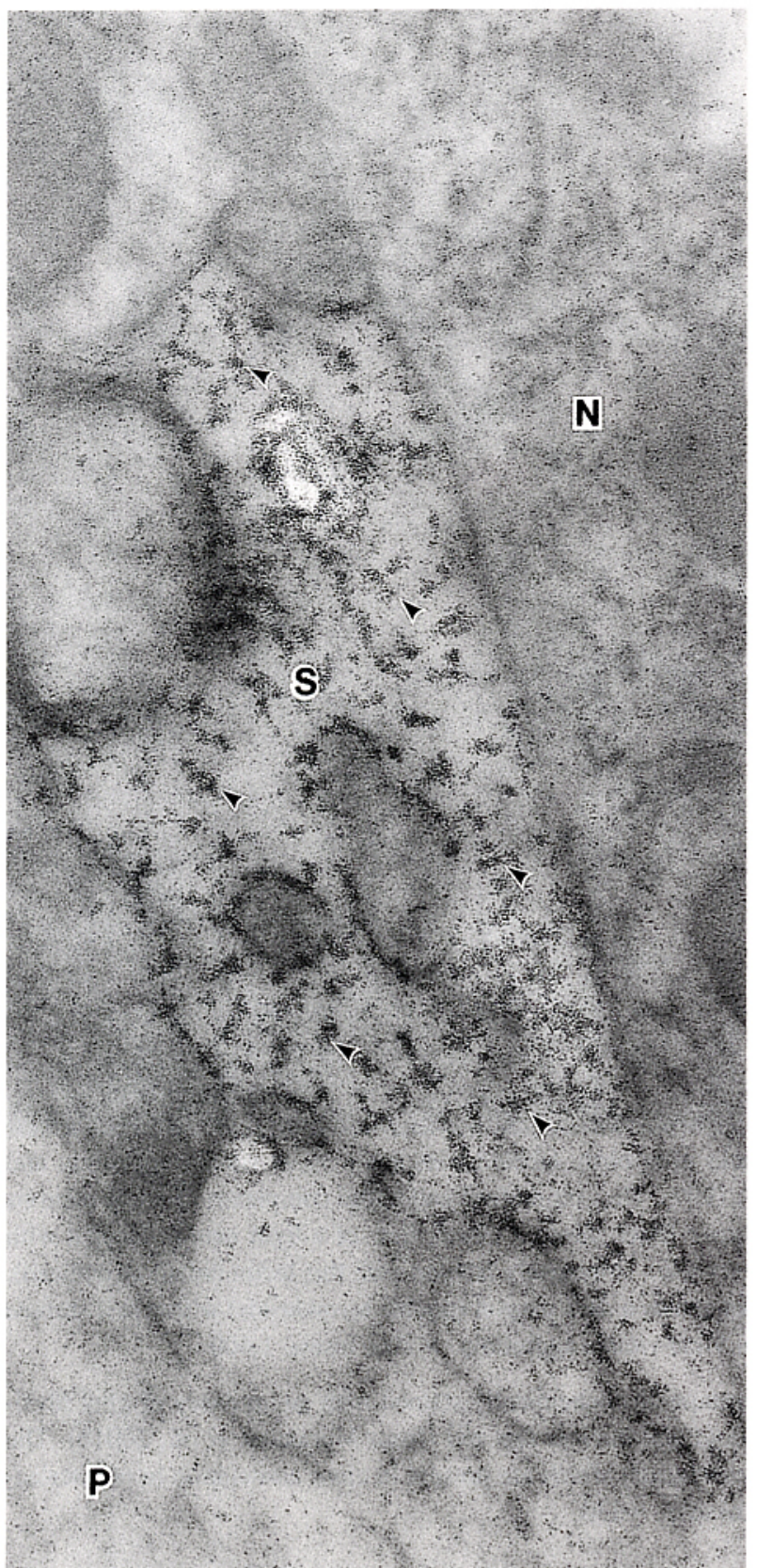

Fig. 10. Transmission electron micrograph of an ultrathin section from the human visual cortex, stained with cationic iron colloid at $\mathrm{pH} 1.0$ and exposed to osmium vapor (from Murakami et al., 1994). It can be clearly confirmed that the clustered iron particles (small arrowheads) are diffusely and preferentially deposited in the perineuronal tissue spaces (S). N: neuronal somata, $\mathrm{P}$ : neuropil region. $\times 100,000$

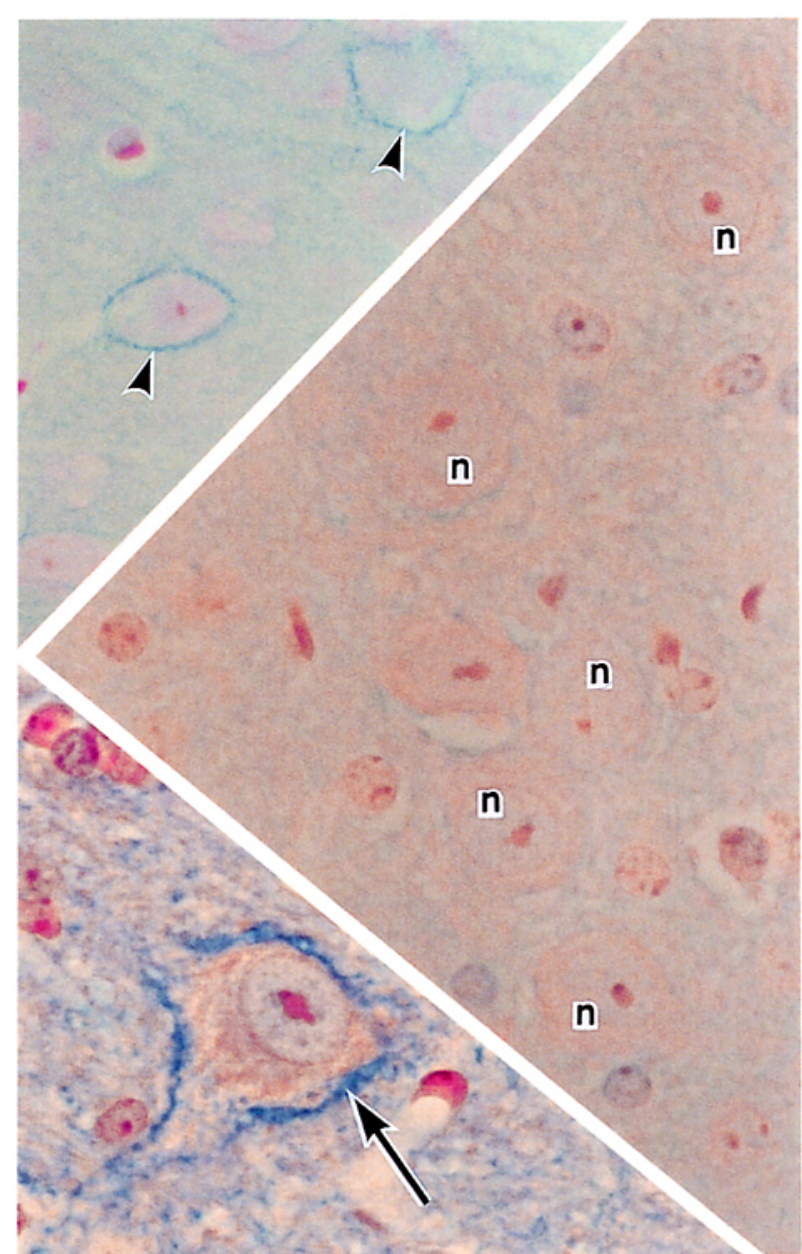

Fig. 11. Large neurons (n) in the cerebellar nucleus of brevican-deficient mice show a marked reduction of cationic iron colloid staining of the perineuronal nets. Upper inset shows that the staining of the nets (arrowheads) is contained in the cerebral cortical neurons from brevican/neurocan-deficient mice. Lower inset shows intensely stained typical perineuronal nets (arrow) seen in the cerebellar nuclear large neuron of wildtype mice. $\times 800$, upper inset: $\times 700$, lower inset: $\times 800$ 
hyaluronan and phosphacan, is accumulated in the perineuronal nets (Hagihara et al., 1999; Brückner ea al., 2000). In tenascin-R-deficient mice, the staining intensity of the perineuronal nets is reduced for brevican, hyaluronan and neurocan. (Brückner et al., 2000).

\section{Link proteins}

Link proteins mediate the linkage of core proteins to the hyaluronic acid. We have recently prepared polyclonal antibodies against brain specific link proteins of perineuronal proteoglycans (Hirakawa et al., 2000; Oohashi et al., 2002; Bekku et al., 2003), and stained mouse brain sections with these antibodies and cationic iron colloid. This has revealed that some neurons are doubly stained with the antibody and cationic iron colloid, and others solely with cationic iron colloid (Murakami et al., 2001b). The details of these findings will be reported elsewhere.

\section{Perisynaptic barrier}

It is well known that tissue proteoglycans (their sulfate groups) entrap tissue fluid and form a gel (Guyton and Hall, 1996). We consider that the perineuronal proteolglycans entrap tissue fluid, and form a "perisynaptic barrier" — a gel layer surrounding the synapses which are the fundamental functional unit of the nervous system (Murakami et al., 2001b). It may be difficult for the tissue molecules to flow easily through this perisynaptic barrier of proteoglycans. Recent studies have indicated that degradation of the perineuronal proteoglycans or our perisynaptic barrier by treatment with chondroitinase $\mathrm{ABC}$ or hyaluronidase reactivates the plasticity of the visual cortex (Pizzorusso et al., 2000; Fox and Caterson, 2002) or promotes the functional recovery of a severed spinal cord (Bradbury et al., 2002; Moon et al., 2003). Snow et al. (1990) suggested that the perineuronal proteoglycans control the neurite outgrowth. Thus, Yamaguchi and his associates proved that the chondroitin sulfate proteoglycan brevican inhibits neurite outgrowth from the granule neurons in the rat cerebellum (Yamada et al., 1997), while heparan sulfate proteoglycan syndecan-2 induces the maturation of dentritic spines in rat hippocampal neurons (Ethell and Yamaguchi, 1999).

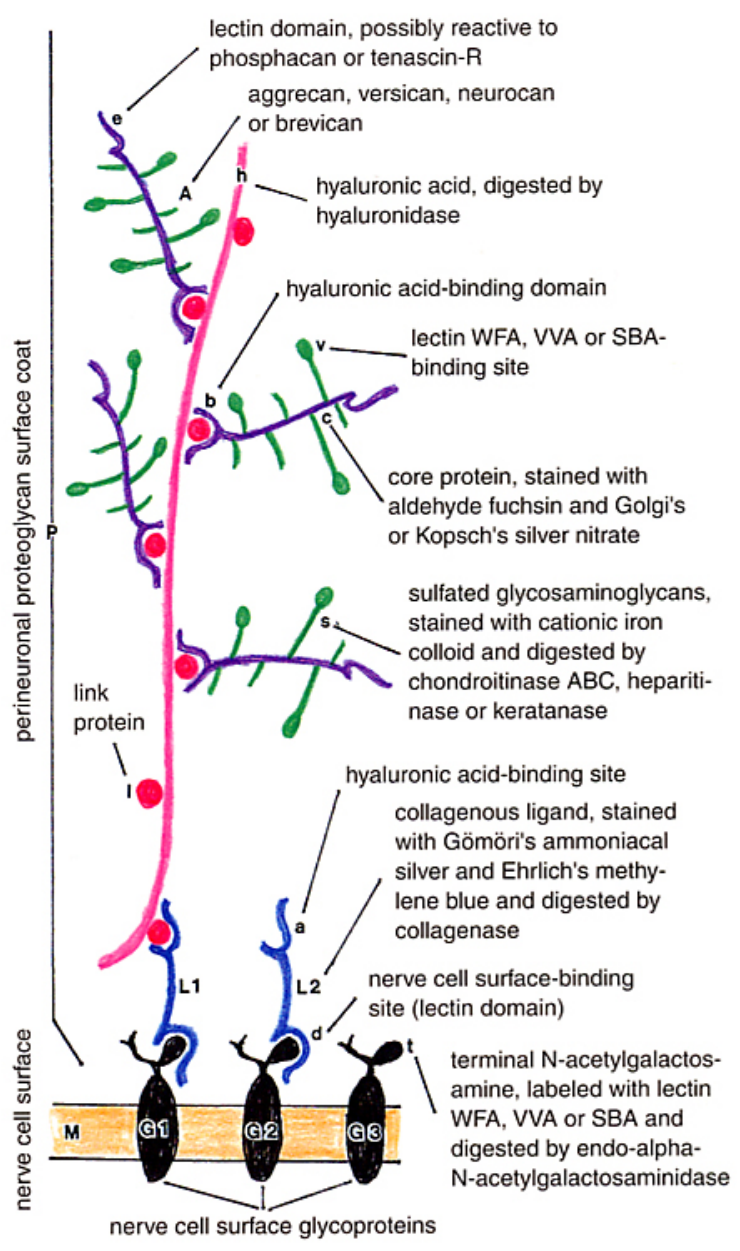

Fig. 12. A hypothetical model of perineuronal proteoglycans and their association with the nerve cell surface (modified after Murakami et al., 1999c). A: aggrecan, vercan, neurocan or brevican, G1-G3: cell surface glycoproteins with terminal Nacetylgalactosamines (t), L1-L2: collagenous ligands with nerve cell surface-binding (d) and hyaluronic acid-binding (a) sites, M: cell membrane or the nerve cell surface, P: perineuronal net of proteoglycans (perineuronal proteoglycan surface coat), b: hyaluronic acid-binding domain, c: core protein, e: lectin domain possibly reactive to phosphacan or tenascin-R, h: hyaluronic acid, l: link protein, s: sulfated glycosaminoglycans, $v$ : lectin-binding site of glycosaminoglycans. 


\section{Hypothetical model}

Our histochemical stainings and enzyme digestions (see above) indicate that the cationic iron colloid stains the sulfate groups of glucosaminoglycans; Fujita's aldehyde fuchsin and Golgi's silver nitrate stain the core proteins (especially, their -s-s- groups), and Gömöri's ammoniacal silver and Ehrlich's methylene blue stain the collagenous ligands (Murakami et al. 1999a, b). These findings are depicted as a hypothetical model in Figure 12. It is well known that types IV, VIII, XV and XVIII collagens occur in the brain (Murakami et al., 2001b). However, it remains unknown as to what types of collagens are contained in the collagenous ligands of the proteoglycans. In regard to the linkage of the perineuronal proteoglycans to the nerve cell surfaces, some authors have offered a different view that the cell surface proteoglycans such as neurocan C, NG2, and a receptor protein tyrosine phosphate isoform related phosphacan may mediate the linkage of the perineuronal proteoglycans to the nerve cell surfaces (Fox and Caterson, 2002). Other authors describe the core proteins of the perineuronal proteoglycans as possibly mediating the linkage of the perineuronal proteoglycans to the nerve cell surfaces (Köppe et al., 1997b). Some other authors (Rauch, 1997; Seidenbecher et al., 2002) have regarded the brevican as a mediator for such linkage.

\section{Intensely positively charged perineuronal nets}

Our recent light microscopic observations of healthy adult rat brain sections stained with anionic iron colloid indicate some neurons in the hippocampal subiculum and all neurons in the medial cerebellar nucleus possess intensely positively charged perineuronal nets (Murakami et al., 2001c, d). These nets react to oxine, and therefore suggest a composition of guanidino compounds. These intensely positively charged nets, in accordance with the intensely negatively charged perineuronal nets of proteoglycans, are digested by chondroitinase $\mathrm{ABC}$, hyaluronidase, and collagenase, but not by endo-alpha- $\mathrm{N}$-acetylgalactosaminidase. This finding suggests that the former positively charged nets might be linked to the latter negatively charged ones of proteoglycans.

\section{References}

Atoji Y, Suzuki Y: Chondroitin sulfate in the extracellular matrix of the medial and lateral superior olivary nuclei in the dog. Brain Res 585: 287-290 (1992).

Bekku Y, Su WD, Hirakawa S, Fässler R, Ohtsuka A, Kang JS, Sanders J, Murakami T, Ninomiya Y, Oohashi, T: Molecular cloning of Bral2, a novel brain-specific link protein, and immunohistochemical colocalization with brevican in perineuronal nets. Mol Cell Neurosci (2003, in press).

Bertolotto A, Rocca, G, Schiffer D: Chondroitin 4-sulfate proteglycans form an extracellular network in human and rat central nervous system. I Neurol Sci 100: 113-123 (1990).

Bignami A, Asher R, Perides G: Co-location of hyaluronic acid and chondroitin sulfate proteoglycans in rat cerebral cortex. Brain Res 579: 173-177 (1992).

Blümcke I, Eggli P, Celio MR: Relationship between astrocytic processes and "perineuronal nets" in rat neocortex. Glia 15: 131-140 (1995).

Bradbury EJ, Moon LD, Popat RJ, King VR, Bennett GSB, Patel PN, Fawcett JW, McMahon SB: Chondroitinase $\mathrm{ABC}$ promotes functional recovery after spinal cord injury. Nature 416: 589-590 (2002).

Brakebusch C, Seidenbecher CI, Rauch U, Matthles H, Meyer H, Krug M, Bockers TM, Zhou X, Kreutz MR, Montag D, Gundelfinger ED, Fässler R: Brevican-deficient mice display impaired hippocampal CA1 long-term potentiation but show no obvious deficits in learning and memory. Mol Cell Biol 22: 7417-7427 (2002).

Brückner G, Brauer K, Härtig W, Wolff JR, Rickmann MJ, Derouiche A, Delpech B, Gigard N, Oertel WH, Reichenbach A: Perineuronal nets provide a polyanionic, glia-associated form of microenvironment around certain neurons in many parts of the rat brain. Glia $8: 183-200$ (1993).

Brückner G, Härtig W, Kacza J, Seeger J, Welt K, Brauer $\mathrm{K}$ : Extracellular matrix organization in various region of rat grey matter. J Neurocytol 25: 333-346 (1996).

Brückner G, Bringmann A, Härtig W, Köppe G, Delpech $\mathrm{B}$, Brauer K: Acute and long-lasting changes in extracellular-matrix chondroitin-sulphate proteoglycans induced by injection of chondroitinase $\mathrm{ABC}$ in the adult rat brain. Exp Brain Res 121: 300-310 (1998).

Brückner G, Grosche J, Schmidt S, Härtig W, Margolis RU, Delpech B, Seidenbecher Cl, Czaniera R, Schachner M: Postnatal development of perineuronal nets in wildtype mice and in a mutant deficient in tenascin-R. $J$ Comp Neurol 428: 616-629 (2000).

Celio MR, Blümcke I: Perineuronal nets-a specialized form 
of extracellular matrix in adult nervous system. Brain Res Rev 19: 128-145 (1994).

Celio MR. Spreafico R, De Biasi S, Vitellaro-Zuccarello L: Perineuronal nets: past and present. Trends Neurosci 21: 510-515 (1998).

Derouiche A, Härtig W, Brauer K, Brückner G: Spatial relationship of lectin labelled extracellular matrix and glutamine synthetase-immunoreactive astrocytes in the cortical forebrain regions. $J$ Anat 189: 363-372 (1996).

Drake CT, Mulligan KA, Wimpey TL, Hendrickson A, Chavkin C: Characterization of Vicia villosa agglutininlabeled GABAergic interneurons in the hippocampal formation and in acute dissociated hippocampus. Brain Res 554: 176-185 (1991).

Ethell IM, Yamaguchi Y: Cell surface heparan sulfate proteoglycan syndecan-2 induces the maturation of denritic spines in rat hippocampal neurons. J Cell Biol 144: 575586 (1999).

Fox K, Caterson B: Freeing the brain from the perineuronal net. Science 298: 1187-1189 (2002).

Golgi C: Intorno all struttura delle cellule nervose. Arch Ital Biol 30: 60-71 (1898).

Guyton AC, Hall JE: The microcirculation and lymphatic system: capillary fluid exchange, interstitial fluid, and lymph flow. In: Textbook of medical physiology (Guyton AC, Hall JE ed), W.B. Saunders Co., Philadelphia-London-Toronto-Montreal-Sydney-Tokyo, 1996 (p. 183208).

Hagihara K, Miura R, Kosaka R, Berglund E, Ranscht B, Yamaguchi $Y$ : Immunohyistochemical evidence for the brevican-renascin- $\mathrm{R}$ interaction: colocalization in perineuronal nets suggests a physiological role for interaction in the adult rat brain. J Comp Neurol 410: 256-264 (1999).

Härtig W, Brauer K, Brückner G: Wisteria floribunda agglutinin-labeled nets surround parvalbumin-containing neurons. Neuroreport 3: 869-872 (1992).

Härtig W, Brauer K, Bigl V, Brückner G: Chondroitin sulphate proteoglycan-immunoreactivity of lectin-labelled perineuronal nets around parvalbumin-containing neurons. Brain Res 635: 307-311 (1944).

Hirakawa S, Oohashi T, Su WD, Yoshioka H, Murakami T, Arata J, Ninomiya Y: The brain link protein-1 (BRALI): cDNA cloning, genomic structure, and characterization as a novel link protein expressed in adult brain. Biochem Biophys Res Commun 276: 982-989 (2000).

Hong, LJ, Mubarak WAE, Sunami Y, Murakami S, Fuyama Y, Ohtsuka A, Murakami T: Enhanced visualization of weak collolidal iron signals with Bodian's protein silver for demonstration of perineuronal nets of proteoglycans in the central nervous system. Arch Histol Cytol 63: $459-465$ (2000).
Kosaka T, Heizmann CW: Selective staining of a population of parvalbumin-containing GABAergic neurons in the rat cerebral cortex by lectins with specific affinity for terminal $N$-acetylgalactosamine. Brain Res 483: 158-163 (1989).

Köppe G, Brückner G, Brauer K, Härtig W, Bigl V: Developmental patterns of proteoglycans-containing extracellular matrix in perineuronal nets and neuropil of the postnatal rat brain. Cell Tissue Res 288: 33-41 (1997a).

Köppe G, Brückner G, Härtig W, Delpech B, Bigl V: Characterization of proteoglycan-containing perineuronal nets by enzymatic treatments of rat brain sections. Histochem J 29: 11-20 (1997b).

Lipsky NG: On the structure of nerve cells, by C. Golgi. Historical note. J Microsc 155: 3-7 (1989).

Lüth H-J, Fischer J, Celio MR: Soybean lectin binding neurons in the visual cortex of the rat contain parvalbumin and are covered by glial nets. $J$ Neurocytol 21: 211-221 (1992).

Mabuchi M, Murakami S, Matsuoka H, Ohtsuka A, Murakami T: Purkinje cell in the adult cat cerebellar cortex possess a perineuronal net of proteoglycans. Arch Histol Cytol 64: 203-209 (2001).

Margolis RK, Margolis RU: Nervous tissue proteoglycans. Experientia 49: 429-446 (1993).

Matthews RT, Kelly GM, Zerillo CA, Gray G, Tiemeyer M, Hockfield S: Aggrecan glycoforms contribute to the molecular heterogeneity of perineuronal nets. $J$ Neurosci 22: 7536-7547 (2002).

Milev P, Maurel P, Chiba A, Mevissen M, Popp S, Yamaguchi Y, Margolis RK, Margolis RU: Defferential regulation of expression of hyaluronan-binding proteoglycans in developing brain: aggrecan, versican, neurocan, and brevican. Biochem Biophys Res Commun 247: 207-212 (1998).

Moon LD, Asher RA, Fawcett JW: Limited growth of severed CNS axons after treatment of adult rat brain with hyaluronidase. I Neurosci Res 71: 23-37 (2003).

Murakami T, Taguchi T, Ohtsuka A, Kikuta A: Neurons with strongly negative-charged surface-coats in adult rat brain as detected by staining with cationic iron colloid. Arch Histol Cytol 56: 13-21 (1993a).

Murakami T, Taguchi T, Ohtsuka A: The occurrence in the human brain of neurons with strongly negative-charged proteoglycans. Arch Histol Cytol 56: 23-26 (1993b).

Murakami T, Tsubouchi Y, Tsubouchi M, Ohtsuka A, Taguchi T, Kikuta A: The occurrence of rat spinal cord neurons with strongly negative-charged surface coats. Arch Histol Cytol 56: 501-504 (1993c).

Murakami T, Tsubouchi M, Tsubouchi Y, Taguchi T, Ohtsuka A: The occurrence of neurons with strongly negatively charged surface coats in mammalian, avian, reptilian, 
amphibian and piscine brains. Acta Med Okayama 48: 195-197 (1994a).

Murakami T, Ohtsuka A, Taguchi T: Neurons with intensely negatively charged extracellular matrix in the human visual cortex. Arch Histol Cytol 57: 509-522 (1994b).

Murakami T, Hitomi S, Ohtsuka A, Taguchi T: Neurons with perineuronal sulfated proteoglycans in human visual cortex, with special reference to their reactions to lectins. Arch Histol Cytol 58: 357-364 (1995a).

Murakami T, Ohtsuka A, Taguchi T, Piao DX: Perineuronal sulfated proteoglycans and dark neurons in the brain and spinal cord: a histochemical and electron microscopic study of newborn and adult mice. Arch Histol Cytol 58: 557-565 (1995b).

Murakami T, Ohtsuka A, Ono K: Neurons with perineuronal sulfated proteoglycans in the mouse brain and spinal cord: their distribution and reaction to lectin Vicia villosa agglutinin and Golgi's silver nitrate. Arch Histol Cytol 59: 219-231 (1996a).

Murakami T, Ohtsuka A, Piao DX: Perineuronal sulfated proteoglycans in the human brain are identical to Golgi's reticular coating. Arch Histol Cytol 59: 233-237 (1996b).

Murakami T, Murakami T, Hong LJ, Su WD, Piao DX Mahmut N, Ohtsuka A: Perineuronal sulfated proteoglycans and cell surface glycoproteins in adult and newborn mouse brains, with special reference to their postnatal development. Arch Histol Cytol 60: 347-354 (1997).

Murakami T, Murakami T, Sato H, Mubarak WAE, Ohtsuka A, Abe K: Perineuronal nets of proteoglycans in the adult mouse brain, with special reference to their reactions to Gömöri's ammoniacal silver and Ehrlich's methylene blue. Arch Histol Cytol 62: 71-81 (1999a).

Murakami T, Murakami T, Su WD, Ohtsuka A, Abe K, Ninomiya Y: Perineuronal nets of proteoglycans in the adult mouse brain are digested by collagenase. Arch Histol Cytol 62: 199-204 (1999b).

Murakami T, Ohtsuka A, Su WD, Taguchi T, Oohashi T, Murakami T, Abe K, Ninomiya Y: The extracellular matrix in the mouse brain: its reactions to endo-alpha- $\mathrm{N}$ actylgalactosaminidase and certain other enzymes. Arch Histol Cytol 62: 273-281 (1999c).

Murakami T, Murakami S, Fuyama Y, Taguchi T, Ohtsuka A: The extracellular matrix in the mature brain: its reaction to endo-alpha- $\mathrm{N}$-acetylgalactosaminidase and collagenase. Ital J Anat Embryol 106 (2, Suppl 1): 475-480 (2001a).

Murakami T, Ohtsuka A, Oohashi T, Ninomiya Y: Perineuronal connective tissue elements (proteoglycans) in the mature brain and spinal cord (In Japanese). Saibo (Tokyo) 33: 320-323 (2001b).

Murakami T, Ohtsuka A, Matsuoka H, Taguchi T, Murakami T, Abe K, Ninomiya Y: Intensely positively charged perineuronal nets in the adult rat brain as detected by staining with anioinic iron colloid. Arch Histol Cytol 64: 45-50 (2001c).

Murakami T, Kosaka M, Sato H, Ohtsuka A, Taguchi T: The intensely positively charged perineuronal net in the adult rat brain, with special reference to its reactions to oxine, chondroitinase $\mathrm{ABC}$, hyaluronidase and collagenase. Arch Histol Cytol 64: 313-318 (2001d).

Nakagawa F, Schulte BA, Spicer SS: Selective cytochemical demonstration of glycoconjugate-containing terminal $\mathrm{N}$-acetylgalactosamine on some brain neurons. J Comp Neurol 243: 280-290 (1986a).

Nakagawa F, Schulte BA, Wu JY, Spicer SS: GABAergic neurons of rodent brain correspond partially with those staining for glycoconjugate with terminal $\mathrm{N}$-acetylgalactosamine. J Neurocytol 15: 389-396 (1986b).

Ohtsuka A, Taguchi T, Sayed R, Murakami T: The spatial relationship between the perineuronal proteoglycan network and synaptic boutons as visualized by double staining with cationic colloidal iron method and anti-calbindin-D-28K immunohistochemistry in rat cerebellar nuclei. Arch Histol Cytol 63: 313-318 (2000).

Okamoto M, Sakiyama J, Kurazono S, Mori S, Nakata Y, Nakaya N, Oohira A: Developmentally regulated expression of brain-specific chondroitin sulfate proteoglycans, neurocan and phosphacan, in the postnatal rat hippocampus. Cell Tissue Res 306: 217-229 (2001).

Oohashi T, Hirakawa S, Bekku, Rauch U, Zimmermann DR, Su WD, Ohtsuka A, Murakami T and Ninomiya Y: Bral 1, a brain-specific link protein, colocalizing with versican V2 isoform at the nodes of Ranvier in developing and adult mouse central nervous systems. Mol Cell Neurosci 19: 43-57 (2002).

Oohira A, Matsui F, Tokita Y, Yamaguchi S, Aono S: Molecular interactions of neural chondroitin sulfate proteoglycans in brain development. Arch Biochem Biophys 374: 24-34 (2000).

Pizzorusso T, Medini P, Berardi N, Chierzi S, Fawcett JW, Maffei L: Reactivation of ocular dominance plasticity in the adult visual cortex. Science 298: 1248-1251 (2002).

Ramón y Cajal S: La red superficial de las celulas nervosas centrales. Rev Trimest Micrograf (Madrid) 3: 163-178 (1897).

Ramón y Cajal: Reseaux pericellulaires. In: Histologie $d u$ systeme Nerveux de l'Homme et des Vertebres (Azoulay L, transl). Vol. 1, Maloine, Paris, 1909-1911 (p. 155158).

Ramón y Cajal S (1909): Fine structure of neuron. In: Histology of the nervous system of man and vertebrates by Ramón y Cajal (Swanson N, Swanson LW, trans1). Vol. I. Oxford University Press, New York and Oxford, 1995 (p. 128-173). 
Rauch U: Modeling an extracellular environment for axonal pathfinding and fasciculation in the central nervous system. Cell Tissue Res 290: 349-357 (1997).

Rauch U, Gao P, Janetzko A, Flaccus A, Hilgenerg L, Tekotte H, Margolis RK, Margolis RU: Isolation and characteriztion of developmentally regulated chondroitin sulfate and chondroitin/keratan sulfate proteoglycans of brain identified with monoclonal antibodies. $J$ Biol Chem 266: 14785-14801 (1991).

Rauch U, Karthikeyan L, Maurel P, Margolis RU, Margolis RK: Cloning and primary structure of neurocan, a developmentally regulated, aggregating chondroitin sulfate proteoglycan of brain. J Biol Chem 267: 19536-19574 (1992).

Ruoslahti E: Brain extracellular matrix. Glycobiology 6: 313-492 (1996).

Sayed R, Mubarak W, Ohtsuka A, Taguchi T, Murakami T: Histochemical study of perineuronal nets in the retrosplenial cortex of adult rats. Ann Anat 184: 333-339 (2002).

Seeger G, Brauer K, Härtig W, Brückner G: Mapping of perineuronal nets in rat brain stained by colloidal iron hydroxide histochemistry and lectin cytochemistry. $\mathrm{Neu}$ roscience 58: 371-388 (1994).
Seidenbecher CI, Smalla KH, Fischer N, Gundelfinger ED, Kreutz MR: Brevican isoforms associate with neural membranes. J Neurochem 83: 738-746 (2002).

Snow DM, Lemmon V, Carrino DA, Caplan AI, Silver J: Sulfated proteoglycans in astroglical barriers inhibit neurite outgrowth in vivo. Exp Neurol 109: 111-130 (1990).

Takahashi-Iwanaga H, Murakami T, Abe K: Three-dimensional microanatomy of perineuronal proteoglycan nets enveloping motor neurons in the rat spinal cord. $J$ Neurocytol 27: 817-827 (1998).

Yamada H, Fredette B, Shirata K, Hagihara K, Miura R, Ranscht B, Stallcup WB, Yamaguchi Y: The brain chondrotin sulfate proteoglycan brevican associates with astrocytes ensheathing cerebellar glomeruli and inhibits neurite outgrowth from granule neurons. J Neurosci 17 : 7784-7795 (1997).

Yamaguchi Y: Lecticans: organizers of the brain extracellular matrix. Cell Mol Life Sci 57: 276-289 (2000).

Yasuhara O, Akiyama H, McGeer EG, McGeer PL: Immunohistochemical localization of hyaluronic acid in rat and human brain. Brain Res 635: 269-282 (1994).

Winkler S, Stahl RC, Carey DJ, Bansal R: Syndecan-3 and percan are differentially expressed by progenitors and mature oligodendrocytes and accumulate in the extracellular matrix. J Neurosci Res 69: 477-487 (2002). 